Fifth International Conference on Sustainable Construction Materials and

Technologies. http://www.claisse.info/Proceedings.htm

\title{
OPTIMISATION OF SECONDARY WASTE GYPSUM FOR MECHANICAL STABILITY IN ROAD (BASE) AND FOUNDATION
}

\author{
Kande Bure Bai Kamara ${ }^{1}$, Eshmaiel Ganjian ${ }^{2}$ and Morteza Khorami ${ }^{3}$ \\ ${ }^{1}$ Research Student, School of Energy, Construction and Environment, Faculty of \\ Engineering, Environment \& Computing, Built \& Natural Environment Research \\ Centre, Coventry University, Coventry, CV1 2JH \\ ${ }^{2}$ Professor of Civil Engineering Materials, Built \& Natural Environment Research \\ Centre, Faculty of Engineering, Environment \& Computing, Coventry University, \\ Coventry, CVI 2JH \\ ${ }^{3}$ Lecturer in Civil Engineering, School of Energy, Construction and Environment, \\ Faculty of Engineering, Environment \& Computing, Built \& Natural Environment \\ Research Centre, Coventry University, CV1 2JH
}

\begin{abstract}
This research was undertaken to close the knowledge gap in factory gypsum wastes. Tests were prepared on industrial by-products to determine suitability. Phase one tests revealed binary and ternary mixtures of gypsum wastes greater than $40 \%$ showed reduced strength at 7,28 and 90 days. Mixture with the proportions of $15 \%$ V-B5G (Vitamin B5 Gypsum), 37.5\%RAF (Reclaimed Asphalt Filler) and 47.5\%GGBS attained the highest compressive strength of approximately $30 \mathrm{MPa}$ at 28 days. One of the dominant factors that influenced the strength of SYSTEM 2 and $2 \mathrm{~A}$ was the presence of calcium sulphate $-\mathrm{CaSO}_{4}\left(\mathrm{CaO}+\mathrm{SO}_{3}\right)$ in the $\mathrm{PG} / \mathrm{V}-\mathrm{B} 5 \mathrm{G}$ materials, calcium silicate $-\mathrm{CaSiO}_{3}\left(\mathrm{CaO}+\mathrm{SiO}_{2}\right)$ in the $\mathrm{GGBS}$ and the pozzolanic activity $\left(\mathrm{SiO}_{2}\right.$ $\left.+\mathrm{Fe}_{2} \mathrm{O}_{3}+\mathrm{Al}_{2} \mathrm{O}_{3}\right)$ in the RAF. The results suggest there are mixtures in all the SYSTEMS that are suitable for use as road (base) and foundation materials.
\end{abstract}

Keywords: gypsum; reclaimed asphalt filler; quarry waste duct, GGBS; hydraulically bound mixtures; pavement

\section{$1 \quad$ INTRODUCTION}

Concerns about the depletion of natural resources and the effect that meeting the demand for aggregates may have on the environment has increasingly focused attention on the possibility of finding alternatives to naturally occurring materials as mentioned by Sherwood, 2007. The aim of this research was to investigate new replacement materials for cement and / or aggregates in concrete. This research looked at the potential use of nine industrial by-products as alternative to cement. Two different types of factory gypsum wastes: Vitamin B-5 Gypsum (V-B5G) and Plasterboard Gypsum (PG) were used to activate three pozzolanic materials: i) Ground Granulated Blast Furnace Slag (GGBS); ii) Steel Slag Dust (SSD); and iii) 
Reclaimed Asphalt Filler (RAF), combined with By-pass Dust (BPD-C and BPD-H), Medium Hydrate Tailing (MHT) and Quarry Waste Dust (QWD) in different proportions as binary and ternary semi-dry pastes. Recycled aggregates will be used with the novel paste to create concrete. The new replacement materials will reduce the impact the extraction of naturally occurring materials have on the environment.

The cement industry is one of the biggest waste producer industries in the world (Modarres, Ramyar and Ayar 2015). Approximately, 7\% of the global carbon dioxide emissions come from the manufacture of cement (Siddique and Rajor 2012, Li et al. 2013). The manufacture of Portland cement itself is ecologically harmful in that the production of one tonne of cement equates to approximately one tonne of carbon dioxide being expelled into the atmosphere (Neville 2012). Approximately 50\% of greenhouse gas production in the UK come from the construction industry (Dadhich et al. 2015).

Waste management and the use of industrial by-products are important aspects of government policies around the world aimed at re-enforcing current trends regarding the conservation of our natural resources. The increasing shortage of land available for waste disposal, the penalties introduced by local authorities in disposing of waste, and the increased manufacturing of by-products, it is inevitable that increased use of these industrial by-products be explored in pavement and other construction applications to help prevent depletion of virgin materials which is accompanied by environmental degradation and lead to economic problems.

\section{RAW MATERIALS USED IN THE RESEARCH}

\subsection{Chemical Compositions of Raw Materials}

The X-ray Fluorescence (XRF) results of the raw materials used in this research are presented in Table 1.

Table 1: Chemical Oxide Composition of Raw Materials used in Research

\begin{tabular}{|l|c|c|c|c|c|c|c|c|c|}
\hline Sample & BPD-C & BPD-H & SSD & PG & V-B5G & RAF & QWD & MHT & GGBS \\
\hline $\mathrm{SiO}_{2}$ & 12.79 & 4.10 & 9.80 & 0.96 & 0.20 & 35.00 & 34.00 & 0.41 & 33.23 \\
\hline $\mathrm{TiO}_{2}$ & 0.19 & 0.17 & 0.84 & 0.03 & 0.00 & 1.60 & 1.80 & 0.01 & 1.09 \\
\hline $\mathrm{Al}_{2} \mathrm{O}_{3}$ & 3.47 & 1.80 & 2.30 & 0.31 & 0.06 & 12.00 & 12.00 & $<0.02$ & 13.14 \\
\hline $\mathrm{Fe}_{2} \mathrm{O}_{3}$ & 1.88 & 1.50 & 26.00 & 0.27 & 0.04 & 12.00 & 12.00 & 0.05 & 0.52 \\
\hline $\mathrm{MnO}$ & 0.04 & 0.03 & 2.80 & 0.00 & 0.01 & 0.42 & 0.41 & - & 0.33 \\
\hline $\mathrm{MgO}$ & 0.82 & 0.43 & 3.40 & 0.13 & 0.04 & 6.40 & 5.30 & 0.70 & 8.92 \\
\hline $\mathrm{CaO}$ & 44.03 & 39.00 & 43.00 & 40.00 & 41.00 & 12.00 & 14.00 & 73.78 & 39.76 \\
\hline $\mathrm{Na}_{2} \mathrm{O}$ & 1.16 & 0.79 & 0.02 & 0.02 & 0.30 & 1.90 & 2.60 & $<0.013$ & 0.21 \\
\hline $\mathrm{K}_{2} \mathrm{O}$ & 10.06 & 22.00 & 0.02 & 0.09 & 0.00 & 1.20 & 0.87 & 0.01 & 0.45 \\
\hline $\mathrm{P}_{2} \mathrm{O}_{5}$ & 0.12 & 0.02 & 0.93 & 0.02 & 0.00 & 0.47 & 0.56 & 0.00 & - \\
\hline $\mathrm{SO}_{3}$ & 12.22 & 4.00 & 0.23 & 52.00 & 54.00 & 1.30 & 0.99 & 0.17 & 1.12 \\
\hline $\mathrm{LOI}$ & - & - & - & - & - & - & - & 25.75 & - \\
\hline
\end{tabular}




\subsection{Physical Properties of Raw Materials}

The particle size distribution of the raw materials used in this research is shown in Figure 1.

\section{Particle Size Distribution Of Raw Materials Used In The Research}

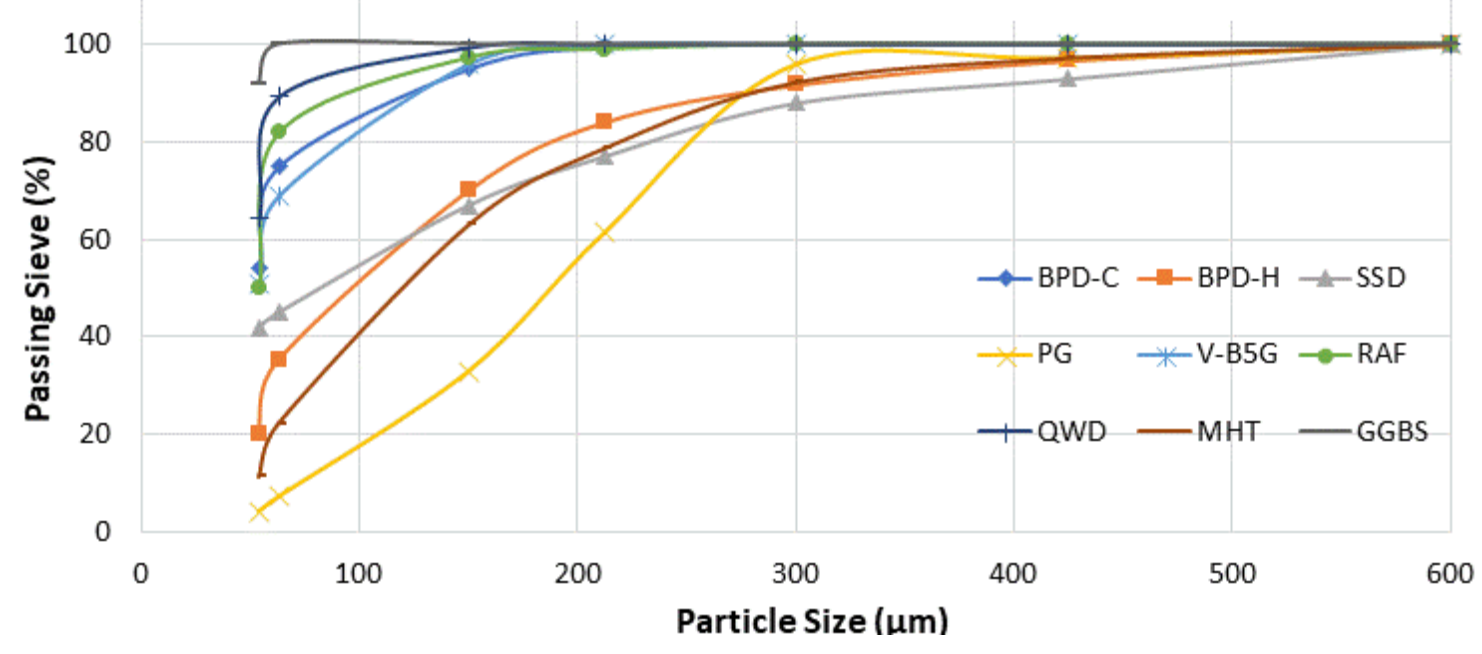

Figure 1: Particle size distribution of raw materials used in the research

Analysis to determine the physical properties were carried out using sieve sizes ranging from 54 microns to 600 microns. The analysis revealed that the V-B5G, RAF, QWD, BPD-C and GGBS contain more particles in the range of 54-212 microns compared to the other samples. The crushed PG contains more particles ranging between $150-300$ microns.

\subsection{Description of Raw Materials}

The raw materials used for this research work include:

Waste plasterboard gypsum (PG) from a local housing development site in Nuneaton, North Warwickshire, UK. The plasterboard waste arose from off-cuts and damaged boards.

Vitamin B5 gypsum (V-B5G), sourced from DSM Nutritional Products UK Ltd, Scotland. This waste gypsum was produced by the pharmaceutical industry. The industrial waste is produced from the manufacture of vitamin B5 (Pantothenic acid) supplements.

Reclaimed asphalt filler (RAF) and quarry waste dust (QWD) from Tarmac. The materials were sourced locally from their Mancetter Quarry in Atherstone, North Warwickshire, UK. The RAF was from their Via Nova Asphalt Plant. 
Medium hydrated tailing (MHT) from Tarmac. This lime product was sourced within the West Midlands, UK. The sample came from their Tunstead - Old Moor Quarry complex, near Buxton that links the Derbyshire - Peak District National Park boundary.

Steel slag dust (SSD) from Tarmac. The material was sourced from their Port Talbot site in Wales, UK.

By-pass dust (BPD-C and BPD-H): Two kinds of by-pass dust were used in this research. BPD-C was sourced from Cemex Rugby Plant in Warwickshire, UK. The BPD-H came from Hanson from the Warwickshire / Leicestershire boundary, UK.

Ground Granulated Blast Furnace Slag (GGBS) from Hanson Heidelberg Cement. The material was obtained from Coventry University materials' inventory stock.

\section{EXPERIMENTAL PROGRAMME}

Laboratory experiments to determine industrial by-products suitability were carried out. Materials identified to have pozzolanic and / or cementitious properties were further explored in the research study. Materials that have neither pozzolanic nor cementitious properties can be used as coarse or fine aggregates if they are considered to have satisfactory mechanical properties that is resistant to crushing.

A statistical mixture design programme - Minitab 18, was used for the Design of Experiment (DoE). Ten combinations of ternary binders referred to as 'SYSTEMS' were designed. The Extreme Vertices Design (EVD) method was used to set the boundaries of the components in each SYSTEM for the designs. Due to the high levels of materials used in some of the components, the combination of binary and ternary mixes was produced in the designs. Most of the SYSTEMS used the same liquid / solid ratio. Specimens in the phase one laboratory tests were evaluated on compressive strength at 7, 14, 28 and 90 days curing.

The pastes were cast in $50 \mathrm{~mm}$ cube moulds. The sample was pre-compacted with a square tamping rod $(25 \mathrm{~mm} \times 25 \mathrm{~mm} \times 300 \mathrm{~mm})$ in three layers of $90 \mathrm{~g}(270 \mathrm{~g}$ total cube mass) per cube at 25 strokes per layer. The sample was further compacted using hydraulic machine. The hydraulic pressure was set at $90 \mathrm{KN}$ for a gang of three set of $50 \mathrm{~mm}$ cube moulds prepared. After the $90 \mathrm{KN}$ load was applied to the sample, it was left for two minutes before it was released. The $90 \mathrm{KN}$ pressure was set to simulate real life application in factory / site environment, whereby a vibrating or pneumatic-tyre roller with a wheel loading of not less than $30 \mathrm{KN}$ followed by at least eight passes is used to compact hydraulically bound mixtures.

The 50mm semi-dry specimens were easy to handle and therefore casting was carried out immediately after the specimens had been hydraulically pressed without a shock or vibration. The specimens were left in open air at room temperature for approximately 12 hours. The specimens were later cured in transparent propagators at $20^{\circ} \mathrm{C}+/-2^{\circ} \mathrm{C}$ with a relative humidity of between $95-98 \%$. Table 2 shows a summary of pastes prepared and tested in the study. 
Table 2: Summary of pastes prepared

\begin{tabular}{|l|l|c|c|c|c|c|}
\hline \multicolumn{2}{|c|}{ SYSTEM } & Test Ages (Days) & $\begin{array}{c}\text { Liquid/Solid } \\
\text { Ratio (\%) }\end{array}$ & $\begin{array}{c}\text { Mixing } \\
\text { Time } \\
\text { (minutes) }\end{array}$ & $\begin{array}{c}\text { Number of } \\
\text { Mixes }\end{array}$ & $\begin{array}{c}\text { Number of } \\
\text { Samples }\end{array}$ \\
\hline 1 & PG/MHT/GGBS & $7 \& 28$ & 15 & 6 & 13 & 117 \\
\hline 2 & PG/RAF/GGBS & $7,28,90 \& 360$ & 15 & 6 & 17 & 153 \\
\hline $2 A$ & V-B5G/RAF/GGBS & $7,28,90 \& 360$ & $15-21$ & 6 & 17 & 153 \\
\hline $2 B$ & PG/RAF/GGBS & $14,28 \& 90$ & 13 & 6 & 13 & 117 \\
\hline $2 \mathrm{C}$ & PG/RAF/GGBS & $14,28 \& 90$ & 17 & 6 & 13 & 117 \\
\hline 3 & PG/GGBS/BPD-C & $7 \& 28$ & 15 & 6 & 13 & 117 \\
\hline 4 & PG/GGBS/BPD-H & $7 \& 28$ & 15 & 6 & 13 & 117 \\
\hline 5 & V-B5G/MHT/SSD & $7 \& 28$ & 15 & 6 & 13 & 117 \\
\hline 6 & V-B5G/RAF/SSD & $7,28 \& 90$ & 15 & 6 & 13 & 117 \\
\hline 7 & V-B5G/SSD/BPD-C & $7,28 \& 90$ & 15 & 6 & 13 & 117 \\
\hline 8 & V-B5G/SSD/BPD-H & $7,28 \& 90$ & 15 & 6 & 16 & 144 \\
\hline 9 & PG/QWD/GGBS & $7 \& 28$ & 15 & 6 & 13 & 117 \\
\hline & \multicolumn{7}{|l|}{ TOTAL } & 167 & 1503 \\
\hline
\end{tabular}

\section{RESULTS OF PHASE ONE EXPERIMENTS}

\subsection{Highest Compressive Strength at 7, 14, 28 and 90 Days}

Mixtures with highest compressive strength at 7, 14, 28 and 90 days on the various SYSTEMS is presented in Table 3.

Table 3: Summary of mixtures with highest compressive strength at 7, 14, 28 and 90 days

\begin{tabular}{|c|c|c|c|c|c|c|c|}
\hline \multirow{2}{*}{ SYSTEM } & \multirow{2}{*}{ Mix Design Reference } & \multicolumn{4}{|c|}{ Strength at Days (MPa) } & \multirow{2}{*}{ L/S Ratio (\%) } & \multirow{2}{*}{ Density $(\mathrm{Kg} / \mathrm{m} 3)$} \\
\hline & & 7 & 14 & 28 & 90 & & \\
\hline \multirow{2}{*}{1 - PG/MHT/GGBS } & Mix 2 - PG40/GGBS60 & - & & 15.94 & - & 15.0 & 1959 \\
\hline & Mix 6 - PG25/MHT15/GGBS60 & 8.13 & & - & - & 15.0 & 1957 \\
\hline \multirow{2}{*}{2 - PG/RAF/GGBS } & Mix 1 - PG20/RAF20/GGBS60 & 1.76 & - & - & - & 15.0 & 1827 \\
\hline & Mix 4 - PG5/RAF47.50/GGBS47.50 & - & - & 27.02 & - & 15.0 & 2002 \\
\hline \multirow{2}{*}{$2 \mathrm{~A}-\mathrm{V}-\mathrm{B} 5 \mathrm{G} / \mathrm{RAF} / \mathrm{GGBS}$} & Mix 1 - V-B5G20/RAF20/GGBS60 & 2.74 & - & - & - & 21.0 & 1930 \\
\hline & Mix 6 - V-B5G15/RAF37.50/GGBS47.50 & - & - & 29.45 & - & 19.5 & 1982 \\
\hline \multirow{2}{*}{ 2B - PG/RAF/GGBS } & Mix 3 - PG10/RAF55/GGBS35 & - & - & - & 33.51 & 13.0 & 1943 \\
\hline & Mix 13 - PG10/RAF30/GGBS60 & - & 8.19 & 16.21 & - & 13.0 & 2012 \\
\hline \multirow{2}{*}{ 2C - PG/RAF/GGBS } & Mix 1 - PG20/RAF20/GGBS60 & - & - & - & 41.24 & 17.0 & 1943 \\
\hline & Mix 13 - PG10/RAF30/GGBS60 & - & 17.52 & 24.78 & - & 17.0 & 2099 \\
\hline \multirow{2}{*}{3 - PG/GGBS/BPD-C } & Mix 4 - PG15/GGBS80/BPD-C5 & 15.45 & & - & - & 15.0 & 1704 \\
\hline & Mix 11 - PG10/GGBS80/BPD-C10 & - & & 22.08 & - & 15.0 & 1783 \\
\hline \multirow{2}{*}{4 - PG/GGBS/BPD-H } & Mix 1 -PG5/GGBF80/BPD-H15 & - & & 25.45 & - & 15.0 & 1900 \\
\hline & Mix 11 -PG28.125/GGBF68.125/BPD-H3.75 & $17.48^{*}$ & & - & - & 15.0 & 1783 \\
\hline $5-\mathrm{V}-\mathrm{B} 5 \mathrm{G} / \mathrm{MHT} / \mathrm{SSD}$ & Mix 1 - V-B5G40/SSD60 & 3.69 & & 9.56 & - & 15.0 & 2188 \\
\hline \multirow{2}{*}{$6-$ V-B5G/RAF/SSD } & Mix 7 - V-B5G5/RAF47.50/SSD47.50 & - & & 11.43 & - & 15.0 & 2153 \\
\hline & Mix 12 - V-B5G10/RAF30/SSD60 & 5.69 & & - & - & 15.0 & 2205 \\
\hline $7-\mathrm{V}-\mathrm{B} 5 \mathrm{G} / \mathrm{SSD} / \mathrm{BPD}-\mathrm{C}$ & Mix 12 - V-B5G20/SSD80 & - & - & 15.62 & - & 15.0 & 2357 \\
\hline \multirow{2}{*}{$8-$ V-B5G/SSD/BPD-H } & Mix 5 - V-B5G5/SSD80/BPD-H15 & 9.48 & & & - & 15.0 & 2526 \\
\hline & Mix 13 - V-B5G12.5/SSD80/BPD-H7.5 & - & & 16.93 & - & 15.0 & 2454 \\
\hline $9-\mathrm{PG} / \mathrm{QWD} / \mathrm{GGBS}$ & - & - & - & - & - & - & - \\
\hline
\end{tabular}




\subsection{Validation for Prediction for SYSTEM 2A}

Figure 2 illustrates the predicted and actual compressive strength results at 28 days for SYSTEM 2A.

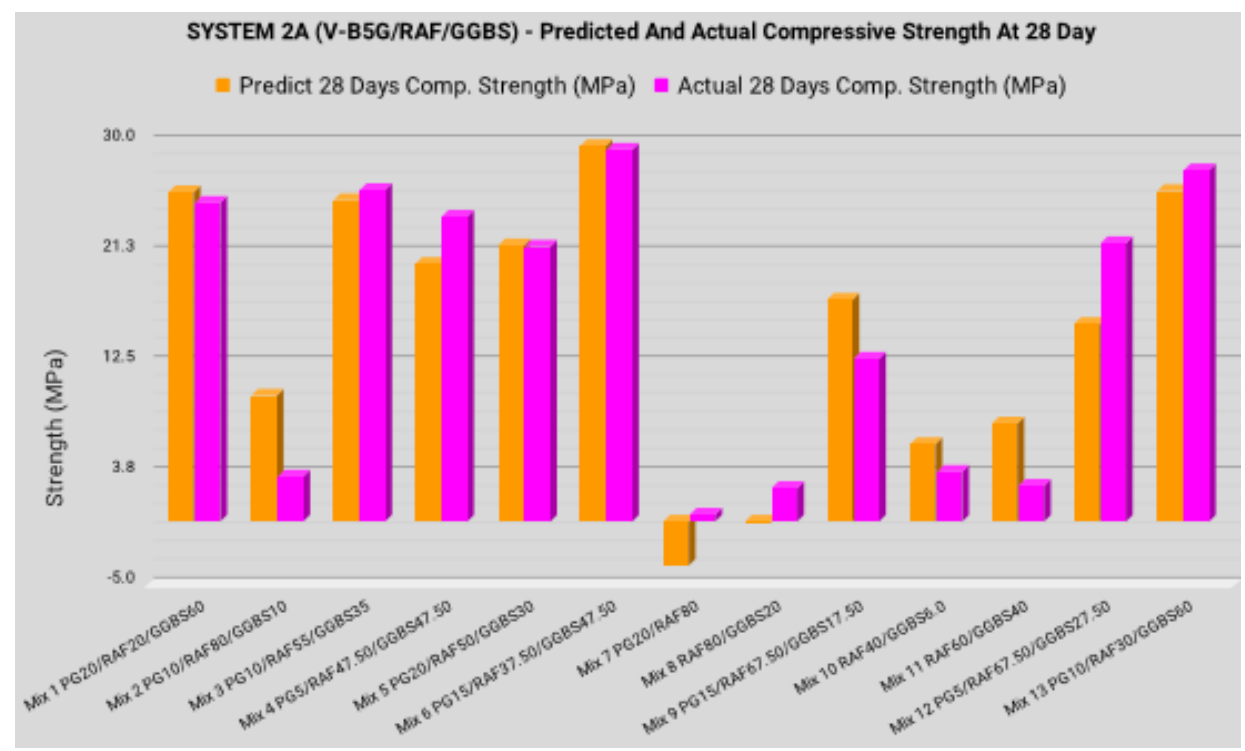

Figure 2: SYSTEM 2A predicted and actual results comparisons

The predicted values are derived from the Coefficient Equation - Eq. 1.

$$
\begin{aligned}
C S= & -753.639(V-B 5 G)-17.2196(R A F)-251896(G G B S)+1006.09 \\
& \left(V-B 5 G^{*} R A F\right)+1175.33\left(V-B 5 G^{*} G G B S\right)+117.031\left(R A F^{*} G G B S\right)
\end{aligned}
$$

Even though the percentage error range vary, the average percentage error for the top four mixes exceeding 25MPa in SYSTEM 2A was $3.25 \%$. Mix $6(\mathrm{~V}-$

B5G15/RAF37.50/GGBS47.50), the highest compressive strength $(29.45 \mathrm{MPa})$ had less than $1 \%$ error. The difference in percentage error in the other mixes in the system could have been number of factors. There is a high probability that the mixture model considered all three materials in the component to have similar mineralogical, physical and chemical properties.

\subsection{Refining the Chosen SYSTEMS}

The compressive strength results for the mixes in SYSTEM 2 (PG/RAF/GGBS) and 2A (V-B5G/RAF/GGBS) showed that they have potential and have exceeded expectation regards to the objectives of this research study. Mix 4 (PG5/RAF47.50/GGBS47.50) in SYSTEM 2 and Mix 6 (V-

B5G15/RAF37.50/GGBS47.50) in SYSTEM 2A had compressive strengths of up to $27 \mathrm{MPa}$ and $30 \mathrm{MPa}$ respectively at 28 days and, have been identified as the optimum mixtures in the phase one experiment. 
As the results of both SYSTEM 2 and 2A were considered to have potentials, further laboratory tests were carried out to determine their optimum performance. Both systems share similar chemical properties. SYSTEM 2 was refined to establish whether the $15 \%$ liquid / solid ratio used in the initial experiment was the optimum moisture content required to achieve its full potential. A liquid / solid ratio of 13 and $17 \%$ was used to determine this. The specimens of the 13 and $17 \%$ ratios were tested at 14, 28 and 90 days. Unlike the tests (7 and 28 days) carried out on the $15 \%$ ratio, the 14 and 90 days tests were to better understand the performance regard to early and long-term strength of the mixtures and, the effect on compaction and hydration.

\section{$5 \quad$ ANALYSIS AND DISCUSSIONS}

\subsection{Evaluation of Hydration and Pozzolanic Effects on the Chosen Systems}

The hydration process is a key element that determines the early and long-term performance of the cement paste. The physical behaviour of cement during hydration is similar to tricalcium silicate $\left(\mathrm{C}_{3} \mathrm{~S}\right)$ and dicalcium silicate $\left(\mathrm{C}_{2} \mathrm{~S}\right)$ compounds alone. These two calcium silicates are the two main cementitious compounds in cement, which together comprise $75-85$ of Portland cements and contribute heavily to binding and strength.

On the mass basis, both silicates require approximately the same amount of water for their hydration. $\mathrm{C}_{3} \mathrm{~S}$ produces more than twice as much calcium hydroxide $\left(\mathrm{Ca}(\mathrm{OH})_{2}\right)$ as is formed by the hydration of $\mathrm{C}_{2} \mathrm{~S}$. When hydration takes place, $\mathrm{C}_{3} \mathrm{~S}$ believes to undergo hydrolysis producing calcium silicate hydrate $\left(\mathrm{C}_{3} \mathrm{~S}_{2} \mathrm{H}_{3}\right)$, with the released lime separating out as $\mathrm{Ca}(\mathrm{OH})_{2}$ (Neville 2012).

According to Eglinton 1987, $\mathrm{C}_{2} \mathrm{~S}$ hydrates much more slowly. The greater part of its hydration does not take place until after about 28 days, but it continues beyond one year. $\mathrm{C}_{3} \mathrm{~S}$ on the other hand contributes to the strength of the cement paste at later age. The slow rate of hydration means that the heat of hydration is low. The hydration reaction of both $\mathrm{C}_{3} \mathrm{~S}$ and $\mathrm{C}_{2} \mathrm{~S}$ is the formation of a gel of calcium silicate hydrate (C$\mathrm{S}-\mathrm{H})$, which is the main binding agent in the cement paste, and of crystalline calcium hydroxide $\left(\mathrm{Ca}(\mathrm{OH})_{2}\right)$.

It was noticeable from the results of the compressive strength tests obtained from this research study that the systems containing pozzolans exhibit slower strength development. Mehta et al. 2014 stated that when blends containing pozzolans are adequately reactive and are used in moderate proportions, and cured for long period under moisture, the strength will increase. This is due to the pore refinement associated with the pozzolanic reaction and the increase in $\mathrm{C}-\mathrm{S}-\mathrm{H}$ and other hydration products at the expense of calcium hydroxide.

Eglinton 1987, stated that the inclusion of pozzolana in a mixture increases the impermeability of the concrete paste, rendering less vulnerable to ingress of aggressive solutions; that as the concentration of $\mathrm{Ca}(\mathrm{OH})_{2}$ in the pore water is reduced the calcium aluminates become more soluble and ettringite is formed in an 
aqueous, not solid, phase and that because of the increased amount of silica contributed by the pozzolan.

Based on the findings of the study carried out by (Abdullah et al. 2012), the strength development behaviour of SYSTEMS 2, 2A, 2B and 2C of this research study is a typical example of pozzolan. Its slower strength development at early age of 7 / 14 days and, longer setting time to achieve its optimum strength at 28 / 90 days did not only show some of the characteristics of pozzolans, it also proof the reaction of $\mathrm{C}_{3} \mathrm{~S}$ and $\mathrm{C}_{2} \mathrm{~S}$ in the constituent.

\subsection{Discussions}

There are two key factors that influenced the strength of the optimum mixes (VB5G15/RAF37.50/GGBS47.50) and (PG5/RAF47.50/GGBS47.50): i) the constituent of the mix itself regards to the proportions of the different materials present; and ii) the percentage of the liquid / solid ratios used in the mixture

It can be said that the dominant factor of calcium sulphate $-\mathrm{CaSO}_{4}\left(\mathrm{CaO}+\mathrm{SO}_{3}\right)$ in the PG / V-B5G materials, calcium silicate $-\mathrm{CaSiO}_{3}\left(\mathrm{CaO}+\mathrm{SiO}_{2}\right)$ in the GGBS and the pozzolanic activity $\left(\mathrm{SiO}_{2}+\mathrm{Fe}_{2} \mathrm{O}_{3}+\mathrm{Al}_{2} \mathrm{O}_{3}\right)$ present in the RAF heavily influenced the performance of the cement paste at both early and late age strengths.

It is also highly likely that the mineralogical properties of the PG / V-B5G may have had a great influence on the strength development of the optimum mixes. (Claisse and Ganjian 2006), distinguished the three main compounds of calcium sulphate and are summarised as follows: i) anhydrite $\left(\mathrm{CaSO}_{4}\right)$ - compound with no water molecules; ii) hemihydrate $\left(\mathrm{CaSO}_{4}-0.5 \mathrm{H}_{2} \mathrm{O}\right)$ - compound with partial water; and iii) dihydrate $\left(\mathrm{CaSO}_{4}-2 \mathrm{H}_{2} \mathrm{O}\right)$ - compound fully hydrated with water and correctly described as gypsum.

The peaks and valleys pattern obtained from the X-ray diffraction (XRD) analysis of the PG and V-B5G showed the presence of high levels of gypsum $\left(\mathrm{CaSO}_{4}-2 \mathrm{H}_{2} \mathrm{O}\right)$ and a moderate level of basanite $\left(\mathrm{CaSO}_{4}-0.5 \mathrm{H}_{2} \mathrm{O}\right)$ also referred to hemihydrate only for the PG. One of the two main industrial uses of these compound mentioned by (Claisse and Ganjian 2006) is in cement. Cement producers use a blend of gypsum and anhydrite as a set controller.

The GGBS used in this research study meets the requirements set out in (EN 2011) for use in blended cement. At least two-thirds of the total mass of slag must consist of the sum of $\mathrm{CaO}, \mathrm{MgO}$ and $\mathrm{SiO}_{2}$. Also, the ratio of the mass of $\mathrm{CaO}$ plus $\mathrm{MgO}$ to that of $\mathrm{SiO}_{2}$ must exceed 1.0. The major oxides present in the GGBS used in this research study were calcium $(\mathrm{CaO})$, aluminate $\left(\mathrm{Al}_{2} \mathrm{O}_{3}\right)$ and silicate $\left(\mathrm{SiO}_{2}\right)$. These three oxides total over 85 percent of the oxide composition present in the sample. The sum of $\mathrm{CaO}$, $\mathrm{MgO}$ and $\mathrm{SiO}_{2}$ of the total mass of slag was more than two-thirds and the ratio of the mass of $\mathrm{CaO}$ plus $\mathrm{MgO}$ to that of $\mathrm{SiO}_{2}$ exceeds 1.0. This did not only show that the material obtained from Hanson Hiedel-berg Cement Group was compliant with (EN 
2011) and suitable for use as blended cement, it also shows that the material had chemical composition that conforms to the criteria for common cements.

The hydration process is another key element that determines the short and long-term performance of the paste mixtures in terms of strength development. It was very noticeable at 28 days strength using 13, 15 and 17\% liquid / solid ratios that 100\% hydration was achieved with the mixtures of $15 \%$ ratio. There was sharp decrease in strength at $13 \%$ compared to a moderate decrease at $17 \%$. There is no doubt that the $15 \%$ water content achieved full compaction and optimum mechanical performance of the mixtures in the system. Figure 3 illustrates the highest compressive strength on SYSTEM 2 with different water content.

It can also be said that the low strength results with mixtures of $13 \%$ ratio was the effect on compaction and not enough water available to carry on during curing time. It was also observed that the mixtures of $17 \%$ ratio was the second strongest in terms of compressive strength achieved at 28 days when compared to the other ratios used in refining SYSTEM 2 (PG/RAF/GGBS). The not so good results for the $17 \%$ ratio compared to the $15 \%$ ratio may have been as the results of less workability in excess water, that evaporates and leaves pores thereby reducing the strength. It clearly shows that the mixtures of $17 \%$ ratio had more than required water that was needed.

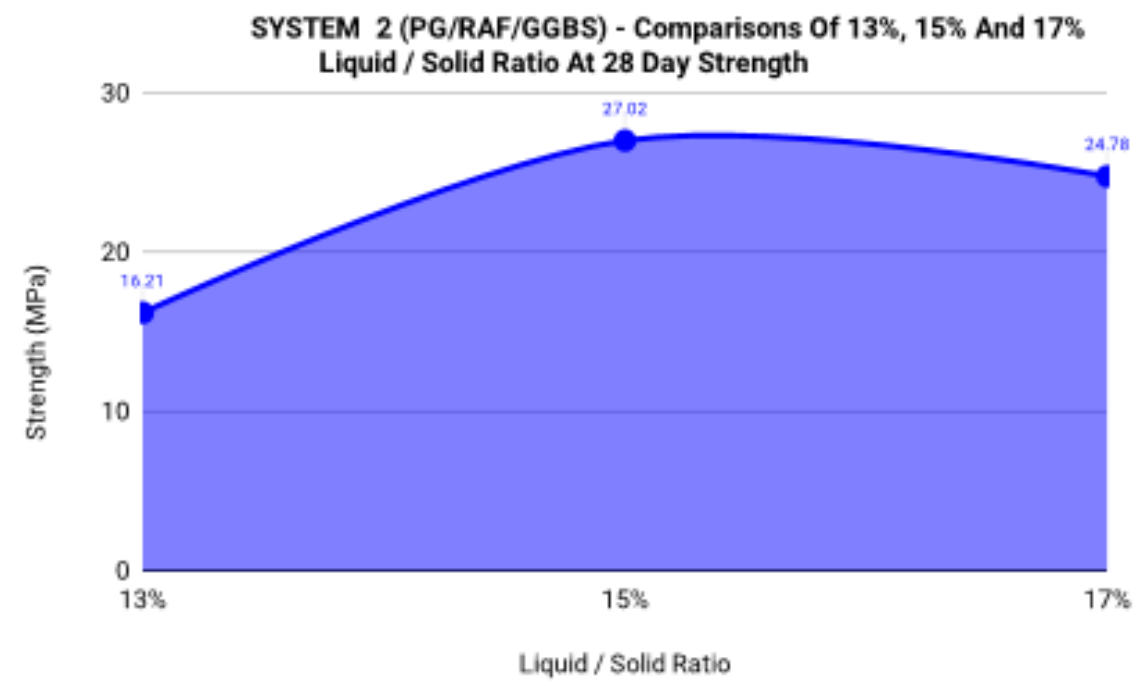

Figure 3: Comparison of replacement of 13, 15 and 17\% liquid / solid ratio

Another factor that may have influenced the mechanical performance of SYSTEMS 2 and $2 \mathrm{~A}$ was the physical properties of the materials in the components. Analysis to determine the particle size distribution of the materials used in the SYSTEM with the highest compressive strength of approximately $30 \mathrm{MPa}$ contain more particles in the range $54-212$ microns. Ganjian et al., 2007 report that pozzolanic materials with a finer particle size results in faster hydration and reduced setting time of the binder. This is due to the higher surface area and electric charges induced on the surface of the particles during the grinding process. 


\section{CONCLUSIONS}

The main conclusions from the research study are:

i) It was proven that it is feasible to fully replace cement with industrial byproducts;

ii) Majority of the mixtures in all the combinations i.e. SYSTEMS that were investigated have potentials to be used not only in highways, but in a wider civil engineering, architecture and building construction applications; and

iii) The dominant pozzolans in SYSTEMS 2 (PG/RAF/GGBS) and 2A (VB5G/RAF/GGBS) with compressive strengths of $27.02 \mathrm{MPa}$ and 29.45 MPa respectively at 28 days, may have been a contributory factor to their success coupled with chemical / physical properties of the materials and the correct water content of $15 \%$ and $19.5 \%$.

\section{REFERENCES}

Abdullah, A., Jaafar, M.S., Taufiq-Yap, Y.H., Alhozaimy, A., Al-Negheimish, A., and Noorzaei, J. (2012). "The effect of various chemical activators on pozzolanic reactivity: A review." Scientific Research and Essays, 7(7),719729.

Claisse, P.A., and Ganjian, E. (2006). "Gypsum: prospects for recycling."

Proceeding for the ICE - Construction Materials, VOLUME 159(1),3-4.

Dadhich, P., Genovese, A., Kumar, N., and Acquaye, A. (2015) "Developing Sustainable Supply Chains in the UK Construction Industry: A Case Study." International Journal of Production Economics 164, 271-284.

Eglinton, M.S. (1987). Construction and its Chemical Behaviour, London, Telford.

EN, B., 2011. 197-1: (2011). "Cement, Composition, Specifications and Conformity

Criteria for Common Cements. ” London, England: British Standard Institution (BSI).

Ganjian, E., Claisse, P.A., and Sadeghi-Pouya, H. (2007). Use of recycled gypsum in road foundation construction, Waste and Resources Action Programme (WRAP), Banbury, Oxon.

Kunal., Siddique, R., and Rajor, A. (2012). "Use of cement kiln dust in cement and its leachate characteristics." Resources, Conservation and Recycling 61, 5968.

Li, J., Tharakan, P., Macdonald, D., and Liang, X. (2013) “Technological, Economic and Financial Prospects of Carbon Dioxide Capture in the Cement Industry."

Energy Policy 61, 1377-1387.

Mehta, P.K., and Monteiro, P.J. (2017). CONCRETE Microstructure, Properties and Materials, $4^{\text {th }}$ Edition. McGraw Hill Education.

Modarres, A., Ramyar, H., and Ayar, P. (2015). "Effect of cement kiln dust on lowtemperature durability and fatigue life of hot mix asphalt." Cold Regions Science and Technology 110, 59-66.

Neville, A. M. (2012). Properties of concrete. $5^{\text {th }}$ Edition. England: Pearson.

Sherwood, P. T. (2007) Alternative materials in road construction: A guide to the use of recycled and secondary aggregates. $2^{\text {nd }}$ Edition, Great Britain, 
MPG Books, Bodwin. 